\title{
A BUSCA DE OUTRAS VOZES SOCIAIS
}

\section{Ler os fatos do mundo a partir de uma perspectiva diferenciada: um bom objetivo para a Imprensa Sindical}

Um trecho da obra Diário de um escritor ${ }^{1}$, de Dostoiévski, conta a história de seis operários que, diante de uma controvérsia, começam a dialogar. Até aí, nada demais. O que há de extraordinário neste diálogo é que ele se dá apenas com uma palavra - a mesma palavra, aliás um "palavrão" - que cada um dos operários profere com entonação, acentuação e sentidos diferentes. Desta forma, Dostoievsky teve a proeza de construir um diálogo com apenas uma palavra.

Mais do que um recurso literário digno de encher as colunas de críticos de arte, este trecho impressionou Mikhail Bakhtin ${ }^{2}$, o grande lingüista russo. Caiu como uma luva para ele confirmar a sua teoria de que o signo é, potencialmente, dialético, pode adquirir distintos índices de valor de acordo com a conjuntura em que ele se situa. Por isto, o signo não é neutro, tampouco um mero instrumento mas a própria expressão da ideologia.

\section{AS MÚLTIPLAS FACES DE UMA PALAVRA}

\section{O AUTOR}

\section{Dênnis de Oliveira}

Jornalista, assessor de comunicação do Sindicato dos Químicos de Guarulhos. Professor de Comunicação Social da Universidade Metodista de Piracicaba (Unimep). Doutorando na ECA-USP e coordenador geral, em São Paulo, da União de Negros pela Igualdade (UNEGRO).
Em fins da década de 70, publicou-se o Relatório da Comissão McBride. Esta comissão, formada no âmbito da Unesco, tinha como objetivo estudar o fluxo internacional de notícias. O monopólio das grandes agências de notícias fazia com que somente uma visão do noticiário internacional fosse propagada, visão esta geralmente desfavorável aos povos do chamado Terceiro Mundo. $\mathrm{O}$

1. cf. DOSTOIÉVSKI. OBRAS COMPLETAS. Rio de Janeiro: Companhia Aguilar, 1963. DOSTOIÉVSKI. PROSA POESIA. São Paulo: Boris Schnaiderman/ Perspectiva, 1982.(N.E.)

2. Mikhail Bakhtin, é autor de, entre outras obras, Marxismo e filosofia da linguagem (2ed., São Paulo: Hucitec, 1981. 196 p.); A cultura popular na Idade Média e no Renascimento: o contexto de François Rabelais (2ed., São Paulo: Hucitec, 1993. 419 p.) e Questões de literatura e de estética: a teoria do romance (3ed., São Paulo: Unesp, 1993. 439 p.).(N.E.) 
Relatório McBride confirmou isto e foi denominado: "Um só mundo, múltiplas vozes".

A procura da multiplicidade de vozes, de concepções, de lados, de índices de valores foi uma constante em minhas buscas pela realização de um outro tipo de trabalho profissional na área de comunicação. As regras quase que absolutas de construção do texto jornalístico não eram a única coisa que me incomodavam. Muito mais do que isto, sentia que várias outras vozes da sociedade eram ignoradas pelos meios de comunicação.

O jornalismo cerca-se de um muro de ferro, cujo clube fechado de fontes e determinados dogmas limitam o universo possível de conhecimento. Sim, porque o jornalismo é uma forma de construir um universo para o conhecimento.

O período da chamada "abertura" do regime militar, iniciada pela dupla Geisel/Golbery e concluída pelo general Figueiredo foi atropelada pela entrada no cenário político - que era e, de certa forma ainda é, um clube restrito - de novos atores sociais: os operários que organizaram as greves metalúrgicas de 1978, 79 e 80, no ABC e em São Paulo; a greve geral de 1983; fundaram centrais sindicais; reorganizaram e construíram partidos políticos socialistas.

$\mathrm{O}$ "clube" fechado da política era ampliado à força, os meios de comunicação tinham novos personagens para as suas histórias. Mas os protagonistas, nas páginas dos grandes jornais e no noticiário do rádio e TV, ainda eram aqueles mesmos. Lembro-me de que, durante os comícios pelas diretas no ano de 1984, fiz uma rápida análise comparativa entre a cobertura jornalística do movimento feita pelas revistas Veja e Isto É. Ambos os periódicos ressaltavam as "novas" personalidades políticas - Ulysses Guimarães, Leonel Brizola, Tancredo Neves, Fernando Henrique Cardoso - que se revezavam nos palanques. A aposta era quem seria o candidato das oposições na sucessão do general Figueiredo, uma vez que era dado como certo o fim do poder dos militares.

E o povo que ia aos comícios? Era como se fosse algo "folclórico", "pitoresco". A Veja, ao lado dos bastidores políticos dos comícios - onde eram enfatizadas as articulações dos membros do "clube" - publicava um quadro com os aspectos pitorescos daqueles seres estranhos que iam às manifestações: "o povo". Finalmente, os meios de comunicação começavam a enxergar mais uma personagem estranha na política: a população.

Mas, para mim, o universo de conhecimento ainda estava extremamente limitado. Por que não incorporar a população como 
protagonista das articulações políticas? É certo que os mais de vinte anos de ditadura militar forjaram uma cultura política autoritária, de decisões de cúpula e isto contaminou, de uma certa forma, toda a sociedade. Aliás, a história do Brasil registra poucos momentos de plena democracia.

\section{UMA OUTRA PRÁTICA}

Com estas preocupações, ingressei no jornalismo sindical em 1986, ano em que concluí o curso de Comunicação Social na ECA. Inicialmente como colaborador eventual de algumas publicações de pequenas entidades, depois como profissional contratado pela Federação dos Químicos de São Paulo, por meio de uma agência de prestação de serviços de imprensa a entidades sindicais.

A experiência na Federação dos Químicos de São Paulo foi importante por diversos motivos. Um deles foi que descobri um potencial a ser explorado no campo da comunicação sindical. Embora a maioria dos sindicatos, atualmente, possuam um órgão de imprensa - um jornal, um boletim, alguns até revistas — poucos têm uma concepção mais formada sobre este órgão, algo que eu chamaria de um projeto de comunicação que estaria coadunado com o projeto político da diretoria do sindicato. Mas foi fácil perceber o porquê. Muitas diretorias sindicais estão mais preocupadas em manter-se à frente do aparelho sindical do que executar um projeto político para as entidades.

A Federação dos Químicos era dirigida por um típico "pelego" oriundo dos tempos da ditadura militar. No momento em que eu ingressei, este dirigente era secretário-geral da Federação, mas na prática era ele quem mandava. Por ser uma entidade de "segundo grau", ou seja, de contato com sindicatos e não de representação direta dos trabalhadores, toda a relação interna na Federação era baseada na "troca de favores" entre dirigentes da Federação, sindicatos e, até mesmo, alguns funcionários. Esta promiscuidade refletia no trabalho da comunicação. $\mathrm{O}$ fascínio pela comunicação, aparecer no jornal, ver seu nome ali, ter suas realizações divulgadas e outras mesquinharias eram fatores de pressão dessas articulações junto ao meu trabalho. Diga-se de passagem, tal tipo de relação também acontecia na agência pela qual fui contratado. Esta agência foi montada por pessoas com as quais eu tinha contato na faculdade e, depois de determinado tempo, as relações dentro da empresa ficaram insuportáveis a ponto de pessoas discutirem por que o nome delas não foi colocado no expediente do jornal! 
No início da atividade da agência, era comum, semanalmente, fazermos uma reunião de conjuntura política, com o objetivo de situar os profissionais que trabalhavam em várias entidades sindicais.

Afinal, o jornalista deve ter uma visão, a mais ampla possível, do que está acontecendo no mundo.

Pois bem, em determinado momento, a maioria dos membros da agência decidiu não continuar com aquelas reuniões sob o argumento de que se estava "fazendo política" e não "trabalho profissional" e que isto iria "destruir a empresa".

Por estas razões, saí tanto da agência como da Federação aliás, as divergências entre o meu trabalho e o dirigente da entidade chegaram a um ponto insuportável - e fui parar no Sindicato dos Químicos de Guarulhos. Este Sindicato era filiado à Federação e não possuía jornalista profissional: os seus boletins e jornais eram produzidos por mim na própria Federação. Como eles conheciam o meu trabalho e estavam num processo de mudanças na orientação política da diretoria, decidiram contratar-me para montar o departamento de comunicação na entidade.

Houve uma situação diferente da de quando eu entrei na Federação. Do ponto de vista pessoal, eu estava mais tarimbado e já tinha perdido parte das ilusões que alimentava quando do ingresso na imprensa sindical. Do ponto de vista mais geral, o projeto de comunicação que eu iria montar acontecia pari passu com a execução de um novo projeto político da diretoria do Sindicato. Por isso, ao contrário da Federação, não peguei o "bonde" andando. E, dentro do novo projeto político da diretoria do Sindicato, tinha grande importância a comunicação.

Neste mesmo momento, estava concluindo meu mestrado em Imprensa Sindical e uma das hipóteses da minha pesquisa era que, ao contrário de algumas teorias centradas numa concepção vulgar do marxismo, a imprensa operária não era um instrumento de "conscientização" e sim, uma forma de ampliar os universos de conhecimento para, a partir daí, formar tanto consciência para ação como ação para a consciência.

Ou seja, a imprensa operária está envolta num projeto maior, não é um fim em si mesma, nem um instrumento, mas um elemento parte de um processo político mais amplo, seja ele desenvolvido por um sindicato, partido ou associação. 


\section{FUNÇÃO DA IMPRENSA SINDICAL}

Influenciou-me muito nestas reconstruções teóricas a obra de Gramsci $^{3}$, particularmente os conceitos de hegemonia e contra-hegemonia; Rosa Luxemburgo ${ }^{4}$ principalmente a obra Greve de massa, partido e sindicatos, os conceitos de classe em si e classe para si de Marx $^{5}$ e outras obras sobre cultura e comunicação popular. De fato, a imprensa sindical não sustenta o seu trabalho apenas divulgando mensagens panfletárias, com conteúdo revolucionário, caso a prática política do sindicato seja totalmente oposta a estas mensagens. Não.

Tendo em vista a burocratização da maioria dos sindicatos, o grande papel da imprensa sindical é democratizar a estrutura sindical, levando o trabalhador a participar, a exigir, a criticar, a criar demandas para a diretoria.

Isto só foi possível realizar em Guarulhos, repito, pelo fato de existir vontade política da diretoria daquela entidade em dinamizar o seu trabalho junto à base. Mas reconheço que esta é uma situação ímpar, não é, infelizmente, a realidade da maioria das assessorias de imprensa das entidades sindicais.

O trabalho no Sindicato dos Químicos de Guarulhos realiza-se com pouquíssimos recursos. Ainda há resistências - não muitas, mas há - em investir na comunicação, vista ainda como "gasto sem retorno". O trabalho de comunicação em sindicato é semelhante à formação escolar: o investimento é a longo prazo, os resultados aparecem depois de um certo tempo e, ainda assim, de forma pontual, muitas vezes não palpável e sem impacto. $\mathrm{O}$ imediatismo dos dirigentes sindicais, preocupados em mostrar serviço, limita a compreensão dos mesmos sobre a importância da comunicação.

3. Antônio Gramsci (1891-1937), revolucionário italiano, fundador do PCI e do jornal L'Unitá. Os conceitos de hegemonia e contra-hegemonia podem ser esclarecidos com a leitura de: Concepção dialética da história (9ed., Rio de Janeiro: Civilização Brasileira, 1991. 341 p.). Outras obras importantes são: Os intelectuais e a organização da cultura (Rio de Janeiro: Civilização Brasileira, 1991. 244 p.) e Literatura e vida nacional (Rio de janeiro: Civilização Brasileira, 1978. 273 p.). (N.E.)

4. Rosa Luxemburgo (1871-1919), revolucionária alemã, fundadora do grupo político Spartakus. Autora de Greve de massas: partidos e sindicatos (2ed., Coimbra: Centelha, 1974. 109 p.); Reforma social ou revolução? e outros textos (Porto: Escorpião, 1975. 146 p.); e Acumulação do capital (Rio de Janeiro: Zahar, 19-?. 516 p.). (N.E.)

5. Karl Marx (1818-1883), teórico revolucionário alemão, fundador da I Internacional e autor de, entre outros, Manuscritos econômicos filosóficos (Lisboa: Edições 70, 1993, coleção Textos filosóficos); O Manifesto Comunista; O 18 Brumário de Louis Bonaparte; A Ideologia alemã; As lutas de classe na França de 1848 a 1850; Miséria da Filosofia; (cf. em Obras escolhidas.São Paulo: Alfa-Omega, [s.d.]); O Capital (3ed., Rio de Janeiro: Civilização Brasileira, 1981). Os conceitos de classe em si e para si estão em: 018 Brumário de Louis Bonaparte e em Miséria da Filosofia.(N.E.) 
Um outro aspecto do trabalho no Sindicato dos Químicos de Guarulhos e que tem um duplo caráter é a ausência de uma proposta política formulada. O Sindicato não é filiado a nenhuma central sindical e a sua diretoria é muito heterogênea do ponto de vista da preferência político-partidária. Por que isto tem um duplo caráter? De um certo modo, não há a cobrança de um engajamento de militância partidária na assessoria, coisa muito comum em sindicatos alinhados com uma corrente partidária, como os filiados à CUT. Em geral, os assessores destes sindicatos são militantes dos partidos dos dirigentes e a relação entre assessoria e assessorado fica ambígua, ora profissional, ora partidária, de acordo com a conveniência da corrente política mais forte. Mas a diretoria do Sindicato de Guarulhos não é, digamos, apolítica, a ponto de ter uma relação meramente administrativa, burocrática. Por isso, acho que, dentro do Sindicato, a visão que se tem do trabalho de comunicação combina - de forma mediática, não oportunista como no caso dos sindicatos alinhados a uma corrente partidária - aspectos profissionais com engajamento. Isto para mim é tranqüilo, pois fui contratado para montar e executar um projeto de comunicação, portanto, de certa forma, sinto-me como um dos "pais" dele.

Mas tem um caráter negativo nesta heterogeneidade de posições políticas da diretoria do Sindicato: fica difícil saber para onde a diretoria quer ir em momentos de embates políticos de maior envergadura. Por exemplo, quando do movimento pelo impeachment de Collor, houve dúvidas dentro da diretoria se o Sindicato deveria apoiar ou não o Fora Collor. Alguns diretores tinham apoiado abertamente Collor nas eleições presidenciais de 1989. O que acaba acontecendo é que, por várias vezes, o Sindicato não toma posição nenhuma para não "rachar" a diretoria, ou toma posições ambíguas, o que é problemático para o trabalho da comunicação.

Um dado interessante e que demonstra isso foi o resultado de uma pesquisa feita com a categoria em fevereiro de 1992. A grande maioria defendeu que o Sindicato se filiasse a uma Central Sindical e que a definição da central se daria por meio de um plebiscito entre os associados. Pois, como a questão é polêmica dentro da diretoria - há quem defenda a CUT, quem defenda a CGT e outros a Força Sindical e, também, aqueles que não defendem nenhuma - o Sindicato não encaminhou essa posição defendida pela maioria dos trabalhadores, a qual, inclusive, sequer chegou a ser divulgada.

Em função deste problema, o trabalho no Sindicato de Guarulhos, embora seja dinâmico, assim como seu jornal, tende a 
ser um tanto provinciano. Pouco se articula com o movimento sindical mais geral, as grandes questões são deixadas de lado, e estas só têm importância quando há uma participação direta de membros da diretoria do Sindicato. Mesmo assim, penso que o discurso expresso no jornal do Sindicato contribuiu para a categoria ter uma visão mais ampla do que ela é - ou uma visão de classe em si - e ter até uma certa consciência dos seus direitos, mas ainda pouco se fala da situação nacional, dos outros trabalhadores, de outras categorias, de outros movimentos.

Fortalece-se, assim, um sentimento corporativo e assistencialista, não no sentido de achar que o sindicato só serve para fornecer convênios, mas que a entidade sindical deve resolver sozinha todos os problemas que ele, trabalhador, tem na empresa.

Na mesma pesquisa que realizamos em 1992 com a categoria, na questão sobre quais os assuntos que os trabalhadores mais gostam de ler no jornal do Sindicato, os mais votados foram: informações sobre salários, saúde e segurança, resolução de problemas nas empresas. Notícias sobre greves, sobre política e economia foram as menos votadas. Isto demonstra que a categoria tem uma visão utilitarista do jornal do Sindicato, assim como do próprio Sindicato. E esta visão utilitarista é reforçada pela diretoria do Sindicato que acredita ser esta a sua função. Isso, para mim, é o resultado da confluência entre o desejo de ter uma entidade sindical dinâmica, com trabalho na base, claramente expresso pela maioria da diretoria do Sindicato dos Químicos de Guarulhos, com a ausência de uma estratégia política definida. Tudo gira em torno, então, do imediato, da manifestação do aqui-agora dos associados.

$\mathrm{Na}$ reformulação que se tenta fazer agora do jornal do Sindicato, esta pressão se tranforma no desejo de fazer do jornal um órgão de prestação de serviços à categoria, com anúncios classificados, informações sobre convênios, lazer etc. Não sou, a princípio, contra isto, mas acho que limitar o jornal sindical a isto é um retrocesso.

É perder a oportunidade de o jornal sindical ser, de fato, um instrumento de ampliação dos horizontes do conhecimento dos trabalhadores, bombardeados pelo noticiário da televisão, rádio e dos grandes jornais.

Mas, de qualquer forma, a batalha não está perdida e acredito que ainda há espaços para explorar este potencial do jornal sindical. 
Finalizando, acredito que ainda há muito a ser debatido sobre a questão da comunicação social no âmbito da esquerda. As teorias apocalípticas que povoaram as pesquisas que se reivindicavam de "marxistas" se, por um lado, desmascararam o mito funcionalista da neutralidade e objetividade, por outro lado levaram a própria esquerda a ter uma visão também funcionalista sobre as possibilidades e potencial da comunicação das classes subalternas. A idéia de que basta construir um discurso revolucionário para estar contribuindo para a conscientização da classe operária deve ser posta de lado. Muito mais do que isto, a comunicação é apenas um dos elementos - e não o único - de todo um sistema social, portanto não é o único e isolado "instrumento de alienação", nem tampouco o único e isolado "instrumento de conscientização". Falta ao campo da esquerda aprofundar mais este debate e constituir teorias que dêem conta da comunicação das classes subalternas.

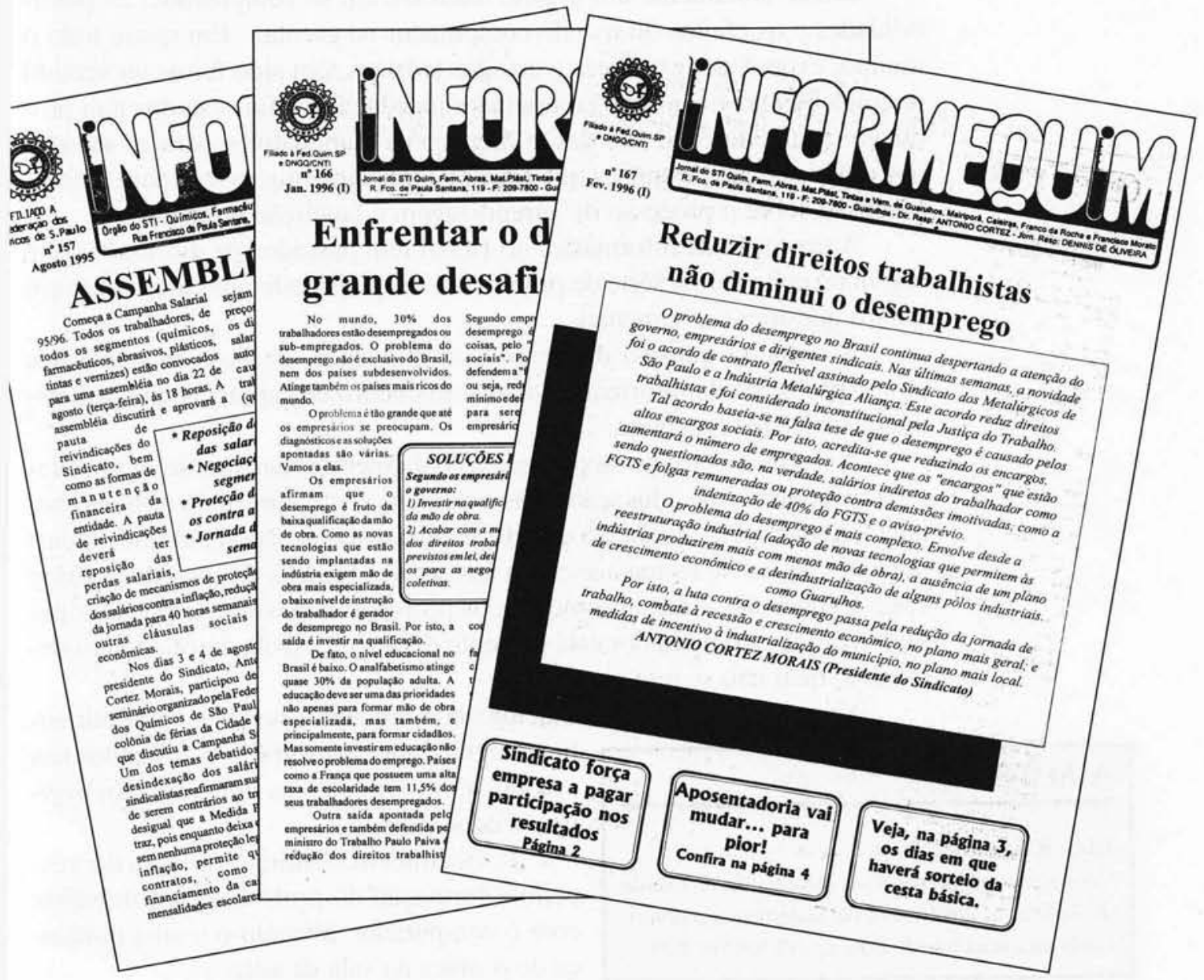

